\title{
Spatial Consequence of Smart City: A Comparison of Online Takeout Service and Restaurant Location in Shanghai Inner City
}

\author{
Feiyang $\mathrm{Ji}^{1}$, Longxu Yan ${ }^{2}$ \\ ${ }^{1}$ Arnold O. Beckman High School, California, United States \\ ${ }^{2}$ College of Architecture and Urban Planning, Tongji University, China
}

\begin{abstract}
Building a smart city is to archive intelligent management and services, thereby promote a more efficient and convenient urban life. However, the spatial impact of smart city technology is not clear. Current literature has focused on online shopping, which we believe produce less spatial impact as another leading application, the online-to-offline business. Taking the online takeout service --one of the most mature online-to-offline application in China--as an example, this paper attempts to provide new evidence for the spatial consequence of smart city implementations. We use open data from the leading online platform to represent the spatial location of conventional restaurants and online takeout shops. Several location metrics are measured and compared between the two shops, including spatial agglomeration intensity, overall accessibility, and distance to current commercial centers, subway station, and street frontages. At the city scale, we found clear evidence that online takeout shops are generally less dependent on agglomeration, and they tend to keep a distance from the conventional commercial centers. Meanwhile, although the location of the two shops in terms of between-ness centrality and distance to subway station is similar, huge difference could be detected when considering sales distribution that the online takeout shops with lower accessibility and larger distance to subway station are having larger market share. This could be explained by the distinct business model of online-to-offline service that shops might rely on online platforms to attract customers instead of spatial heterogeneity, making the spatial competition mechanism less effective any more. Additionally, at the micro level we also characterized the two shops based on distance to street frontages. The result shows that about $12-18 \%$ of the online takeout shops are located away from the street thus could be defined as mixed into the block. Finally, we argue that such process could lead to new development opportunities in the "ordinary" location as well as challenges including social conflict and planning policy barriers.
\end{abstract}

Keywords: Spatial Consequence, Smart City, Online Takeout Service, Restaurant, Shanghai.

\section{Introduction}

One of the fundamental goals of the Smart City is to archive intelligent management and services by promoting a more efficient and convenient urban life. Recently, the Chinese cities are considered to be approaching Smart City both in the public and the private sectors. Several local governments, such as Hangzhou, Shanghai, and Shenzhen, have launched public projects to improve the administration process with cell phone Apps and cloud computing technologies. At the same time, more efficiency and convenience has been created by the private online platforms that targeting at people's daily life. For example, the so-called O2O (online-to-offline) business model, including shopping platforms, online takeout service, household management service, etc. People could just place orders online through cell phone Apps and wait for servicer to come.

However, the spatial impact of such kind of Smart City technology is not clear. Current literature has focused on online shopping and revealed its potential substitutional and complementary effect on conventional retailers. Despite the findings, online shopping could be considered as an exception in terms of spatial impact at intra-urban scale, considering it is able to re-organize the elements of commerce at regional and even global scale. In contrast, most of the Smart City technology may target at more local scale, for instance, a government's online platform for convenient civil service only connect the people with corresponding jurisdictional facilities; an online daily-service website only enables the residents with nearby providers. The evidence of the spatial impact of such kind of Smart City technology is far from enough. 
This paper attempts to provide new evidence of the spatial consequence of Smart City by comparing the spatial location of conventional restaurants and new online takeout shops. We first surveyed the theories that describe the location of conventional retailers, based on which the conventional urban organization could be explained as spatial competition mechanism. Then, we explored the difference between the two shops spatial distribution by measurements including the agglomeration intensity, relationship with commercial centers and subway stations, general accessibility, and distance to street frontages. Finally, through the spatial metrics we discussed new challenges and opportunities along with the Smart City technologies.

\section{Background}

\subsection{Conventional urban Spatial Organization of Retailers}

A conventional urban organization could be explained by the spatial competition mechanism, that is a tendency among the producers to compete for the surrounding residents' and mobile demand with potential interdependence, such as spatial agglomeration, so as to improve their common attractiveness. Current literature provides mainly two perspectives about the retail agglomeration. From the standpoint of the servicers, Hotelling(Hotelling, 1990) believed that competition itself could lead to spatial clustering. The classic Hotelling's law predicts that a street with two shops will also find each serve half the market; one will draw customers from the north, the other all customers from the south, resulting in a clustering of the shops right next to each other at the same halfway point. Additionally, shops may also concentrate spatially due to the retail demand externalities. For instance, the so-called "positive demand externality" describes a phenomenon that smaller and low-order good retailers may benefit from the proximity to some high-order retailers(Brueckner, 1993), which accounts exactly for the importance of the anchor stores in commercial center plans. That means the unequal spatial distribution will distribute the advantages of different stores drastically. This common phenomenon greatly shapes the current retail spatial distribution that incorporates different types of stores which all have abilities to survive under different circumstances.

From the customers' perspective, comparison shoppingmay lead to retail agglomeration as well(Bucklin, 1967). Specifically, customers often reduce their uncertainty by patronizing agglomerated retail sites where they can compare shop, thus reducing the uncertainty of finding a desired item(Webber, 1972). That reveals a preference of the shopping sites with high density and diversity of goods and services, which make such commercial centers generally more attractive to customers due to abundant product options. Finally, governments spatial policy and development plans, such as those focus on facilitating shopping centers, retail streets, and commercial complex, may also stimulate retail agglomeration(e.g., Stokvis and Cloar, 1991). Different rules will both limit (from making one type of store too powerful) and help retail shops to develop(agglomeration) in order to create fair competitions between different shops.

Afterward, the spatial competition mechanism provides an explicit explanation of the urban organization, i.e., the spatial distribution of these retail clusters or commercial centers, by theories such as the central place theory. Christaller (Christaller, 1966)arguedthat every particular good or service has an economic distance, whose lower limit (so-called "threshold") is the minimum market (population or income) needed to bring about the selling, and the upper bound (so-called "range") is the maximum distance consumers are prepared to travel to acquire goods, since in a further distance the cost or inconvenience will outweigh the need for the good. Thus, the rise and fall of a central place depend on the market area, or the hinterland it occupies spatially through competition. Eventually, the central places constitute a hierarchical structure with a triangular lattice pattern, in which the higher order centers will incorporate lower order services. This kind of structure makes the retail patterns consistent and healthy. When applied inside the city, the same process also explains the spatial distribution of the retail clusters. Such a pattern was found in many empirical studies, for instance, Berry (Berry, 1967)showed that the intra-urban retail distribution in Chicago generally accords with the theory, except for being more like a continuum. 
In fact, the spatial characteristics of retail agglomeration also depend on many more factors other than discussed above. These factors could be summarized by location(Applebaum, 1977), including the heterogeneous accessibility of road network and the proximity to commercial centers, transportation nodes (such as subway station), popular facilities (such as stadiums), road crossing, and street frontages. Essentially, the reason why retail shops including restaurants located at these places is the same as the discussed spatial competition mechanism. The only difference is that the homogeneous ideal space in central place theory will be substituted by the realistic heterogeneous urban environment, where the accessibility may be transformed to popularity, and then attract more customers and has a greater potential to develop into a social catalyst. If every circumstance is different, retail stores need to figure out better ways to survive and earn well. Empirical evidence based on theory and metric such as the space syntax has revealed the similar scaling law of retail and services distribution as in the central place theory.

\subsection{Potential Impact of ICT Applications}

The Information Communication Technology (ICT) has long been considered as a challenge for the urban agglomeration. Researchers may argue that with the help of ICT applications business contact may get rid of a face-to-face meeting, paving the recession ways of the rules and characteristics of the conventional retail structure. For example, evidence from online shopping studies explained the effect of substitution (replace physical store) and complementary (enhancement and efficiency for a physical store) to shopping centers(Mokhtarian, 2004; Weltevreden, 2007). The former asserts that customers may reduce the frequency of physical shopping, and the latter argues that online stores may have a complementary effect on the provision of information, online payment, and after-sale services that is a combination of every part of the process. Although such kind of effect has been observed, its spatial impact has not been measured systematically. Future research is needed to delve into issues of the new technology.

Moreover, since online shopping is essentially a reorganization of the trade process regionally instead of intra-urban scale, one may speculate its spatial impact is not as large as another type of ICT application, i.e., the online-to-offline service, which has been actively progressing in China in the past decade. On the one hand, in the $\mathrm{O} 2 \mathrm{O}$ (online-to-offline) service model customers and producers still need to contact physically to fulfill the whole trade. Thus, it may be a lot more sensitive to local urban market, including the rental prices derived from the spatial competition mechanism. On the other hand, producers could attract customers on the virtual online platform instead of through physical contact. Consequently, producers may relocate to achieve lower cost and higher returns, leading to a completely different spatial organization in the coming internet era. The advantages and disadvantages of online shopping affect the physical retail shops, and the shops need to consider well in order to earn better profits. Overall, the impact of $\mathrm{O} 2 \mathrm{O}$, especially on the physical store, is not easy to observe.

\section{Data}

This paper proposes to use open data from catering service websites to evaluate the impact of smart city technology. Online takeout service in China has been expanding fast since 2014. Many online platforms, including ele (https://www.ele.me/), Meituan (http://www.meituan.com/), and Baiduwaimai (https://waimai.baidu.com/), are providing takeout service for local cantering producers. Every takeout shop could register on these platforms and attract customers with features such as price, reviews, specialties, and pictures through search engines. The takeout service data we use is obtained from ele.com, which has the largest market share of 34.1\% during the data collection and is probably the only website that contains locational information of the producers. Thus, we believe the data has a typical representativeness in terms of the booming online takeout industry in Shanghai. The specific dataset we use consists of 6077 takeout shops in Shanghai in September 2015. The average monthly sale number is about 1600 orders, with an average delivery fee of 35.4 RMB Yuan. 
Similarly, we use the data obtained from Dazhongdianping (https://www.dianping.com/), a Chinese answer to Yelp, to represent the spatial distribution of conventional restaurants. Considering it is the largest third-party review websites in China with professional guarantee of its information, we believe in the appropriateness of the dataset. In the cross-sectional dataset of August 2015, Shanghai inner city had about 17486 restaurants, with an average spending of 50.6RMBYuan. Although there is an overlap between the shops in the two datasets because some of them do both offline and online catering service, we believe it causes no discrepancies to the analysis. To see that, consider two sets with an intersection, if we found there is huge difference between them, then the net discrepancies will be a lot more significant after excluding the overlapping shops.

\section{Results}

\subsection{Relationship with Conventional Urban Spatial Structure}

We use two metrics to compare the overall spatial agglomeration of the two shops. One is the Moran I index that measures the global spatial patterns. Report shows that although both of the spatial distribution is significant clustered, the restaurants have a Z-score of 90.4, while the online takeout is only 4.1. Another metric is the kernel density which could provide more explicit visual proof of the general agglomeration. While the restaurants density in many parcels exceed 180 per $\mathrm{km} 2$, as depicted in Figure 1, the online takeout density never surpasses 135 across the whole city. Moreover, the restaurants form explicitly eight spatial concentrations, such as the People's Square, Jing'an Temple, North Sichuan road, and Xujiahui. In contrast, the online takeout has none.

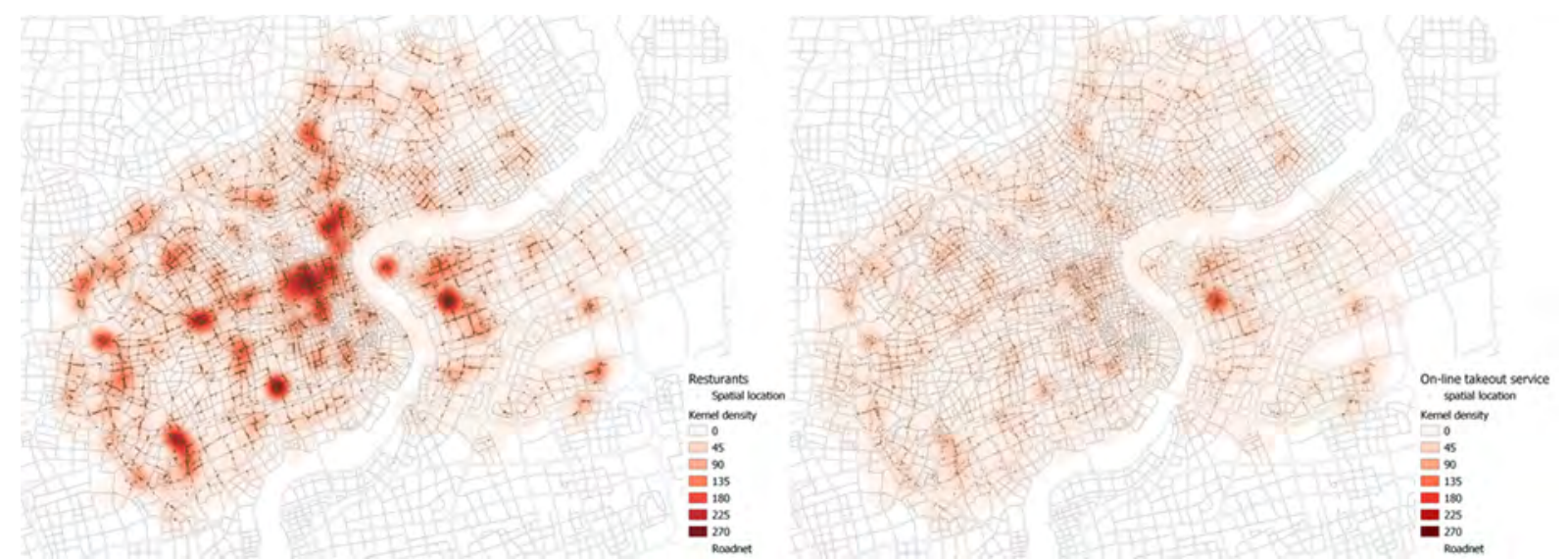

Figure 1. The kernel density of restaurants (left) and online takeout shops (right).

In order to measure the relationship between shop location and urban spatial structure, we calculate the distances of the two shops to the commercial centers in Shanghai identified by (YAN et al., 2016) and then aggregate the spatial distribution statistics. Figure 2 shows a completely different distribution of probability density. The restaurant location is closely related to the commercial centers with a proportion of $60 \%$ shops inside the centers. On the contrary, only $1.3 \%$ of the online takeout producers are covered. Furthermore, as the distance increases, the restaurant shows a generally even distribution, indicating no significant concentration. However, online takeout service demonstrates a clear preference of locations far from the centers. 


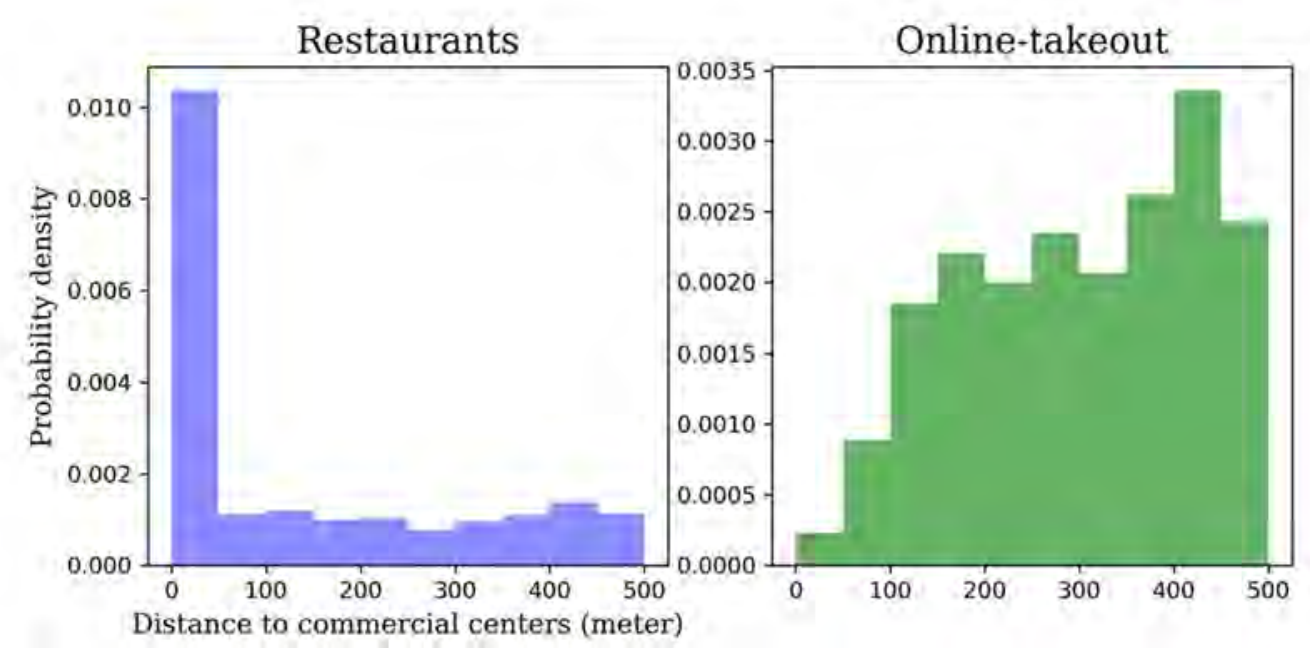

Figure 2. Location of the two shops in terms of distance to commercial centers.

\subsection{General Location Characteristics}

In order to assess the general locational difference of the two shops, we measured two metrics, including proximity to subway station and road network accessibility, both of which could attract retailers by their customer flows, as discussed in the literature.

The role of subway station is implicit. Despite of the ability of gathering massive customer flows, both the two shops shows no preference of being close to the stations. Specifically, at the closest distance to the subway station, there are $7.5 \%$ restaurants and $7 \%$ takeout stores. On the contrary, there are $18.5 \%$ restaurants and $19.5 \%$ takeout shops located farther away from the subway station. However, when we measured the distribution of sales in terms of distance to subway stations, new trends came to obvious. While the sales/remarks of restaurants tend to decline along with the distance to subway stations, the sales of online-takeout shops are having an opposite trend. As the distance increases from 50 to 500, the restaurants' sale decline from 900 to 380, while for the online takeout shops it rises from 1000 to 1900 .In general, it indicates that to some extent the online takeout shops are not sensitive to conventional locational factors any more.

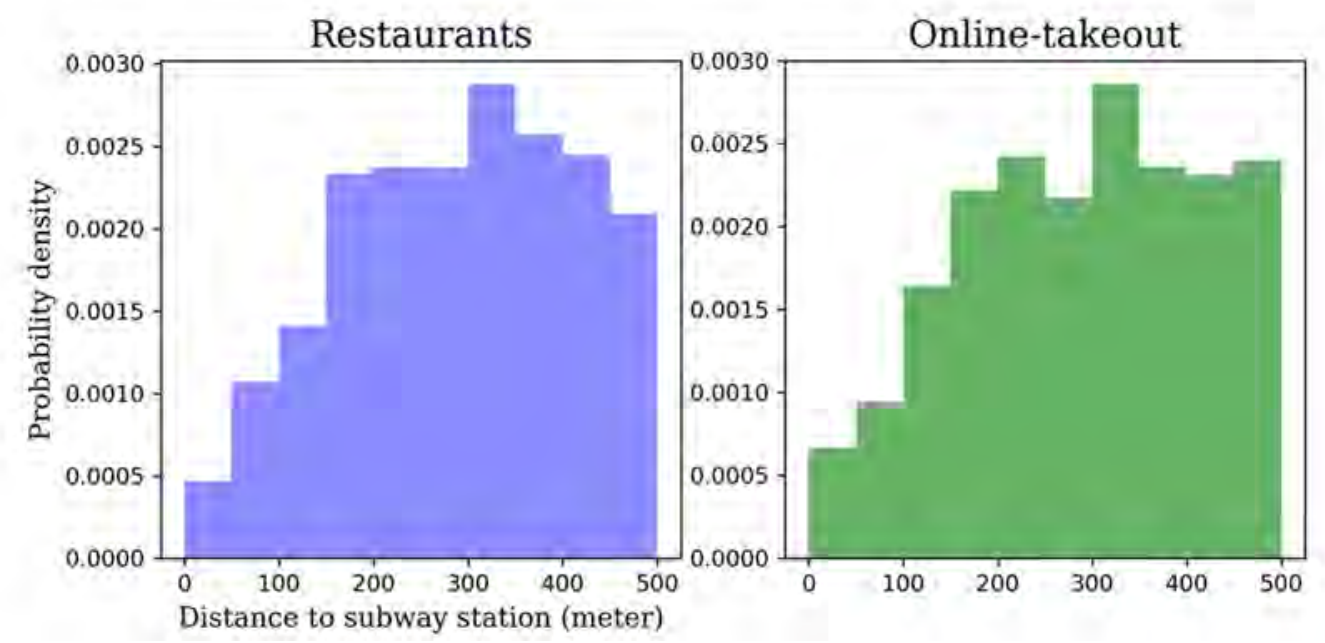

Figure 3. Location of the two shops in terms of distance to subway stations. 

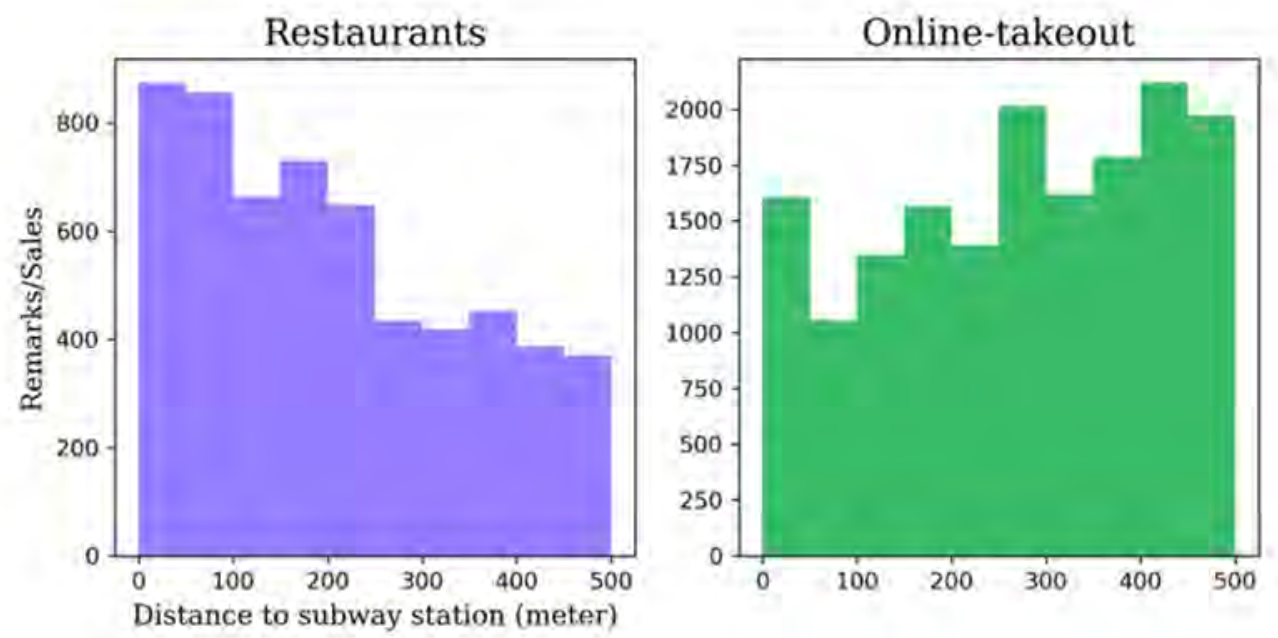

Figure 4. Sales of the two shops aggregated by distance to subway stations.

The same phenomenon could be observed when we tried to characterize the two shops by a more comprehensive metric of urban accessibility, i.e., the between-ness centrality of the road network. Basically, the metric computes the sum of the fraction of all-pairs shortest paths that pass through an edge, thus is proved to have a strong correlation with traffic flows in many empirical studies (Porta et al., 2009). We divided the street segments into ten groups with quantile break, in which the group with larger index represents $10 \%$ of the segments with better between-ness centrality. Then we counted again the locational distribution of the two shops as well as their sales in terms of betweenness centrality of the nearest street segment. Theoretically, there is a strong probability that a street with higher between-ness centrality is able to attract more traditional retailers.

Although the result in Figure 5 confirms that both shops have a preference of location with higher between-ness centrality, no significant difference is found between them. However, when counting the sale amounts we found again a significant difference that the takeout shops located at lower accessibility streets tends to have a much higher market share. As depicted in Figure 6, the sales of restaurants increase about 3 times when between-ness centrality changes from index 1 to 10 , while takeout sales decrease about 50\%. Given that many factors other than accessibility, such as rent, land use and building construction, are affecting the location of shops in the real world, the little difference of location in terms of road network accessibility is actually acceptable. But the fact that online takeout servicers at the most inaccessible location gains the largest amount of sales still unfold a ubiquitous reality that Smart City technology has reversed the mechanism of urban spatial organization.
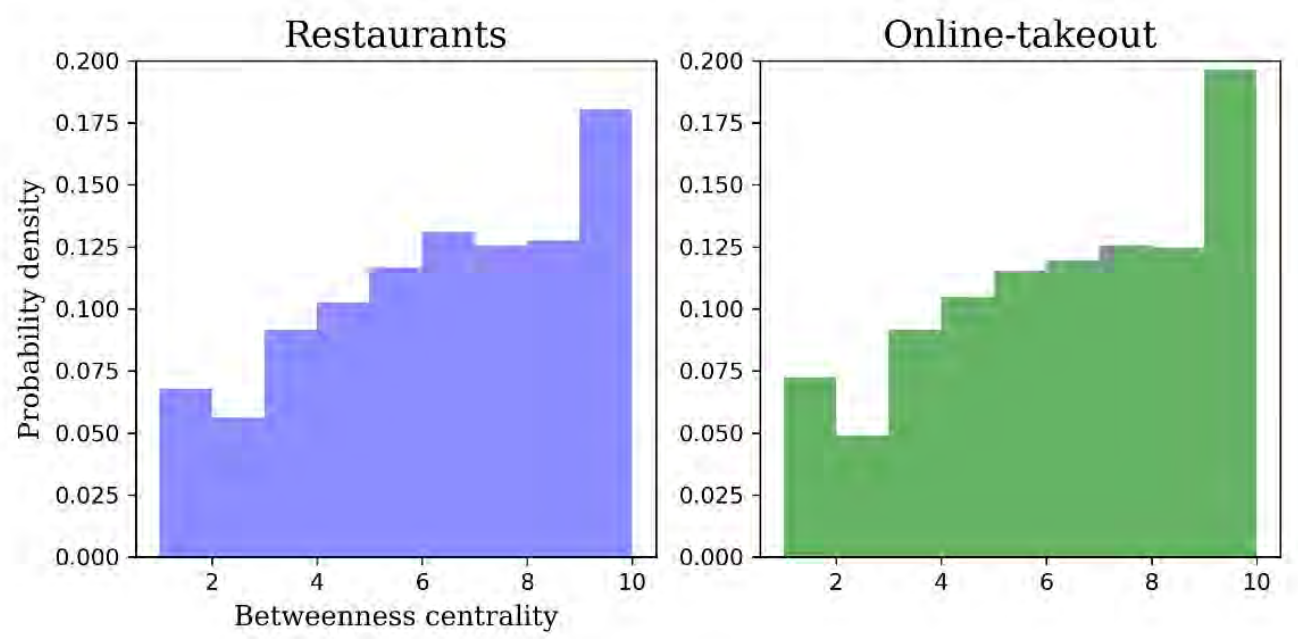

Figure 5. Location of the two shops in terms of roadnetwork accessibility. 

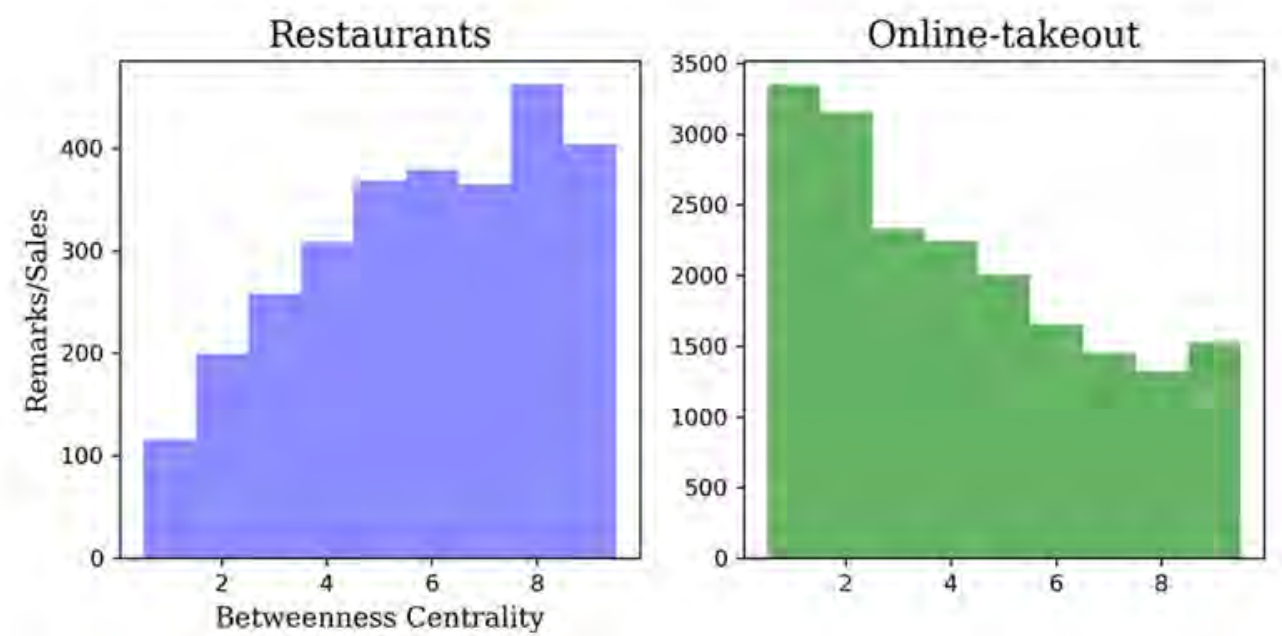

Figure 6 . Sales of the two shops aggregated by road network accessibility.

\subsection{Detailed Location Characteristics}

Additionally, one of the most important characteristics we found is the location of the two shops in terms of distance to street frontages. At the micro level, there are basically two ways of being a retailer in conventional urban environment. One is to be located in the shopping malls or commercial complexes and gain the most benefit from the agglomeration, the other is to located at the accessible streets with afront door faces to the public space. Here we measure the location characteristics of the two shops in terms of the second type. We calculated the distance of each shop to the street frontage, which is represented by the "red line" in China's zoning regulation, and then aggregated the probability density of the two shops by the distance. The result in Figure 7 shows a comparatively similar diagram. However, when count the detailed probability we found something extraordinary. About $95 \%$ of the restaurants are located no further than 40 meters from the street frontage, while the number for online takeout stores is only $82 \%$. Although the threshold of 40 meters is an arbitrary choice, it does have some implication that most of the buildings along with the street facade have a depth less than 40 meters, indicating that most of the shops located 40 meters away from the street frontages could be defined as mixed into the block. In other words, in Shanghai inner city area, about 1,100 online takeout shops have "relocated" to the inside of the blocks. Given a little adjustment, only $2 \%$ of the restaurants have a distance larger than 60 meters, while the number for online takeout services is $12 \%$, about 730 shops.
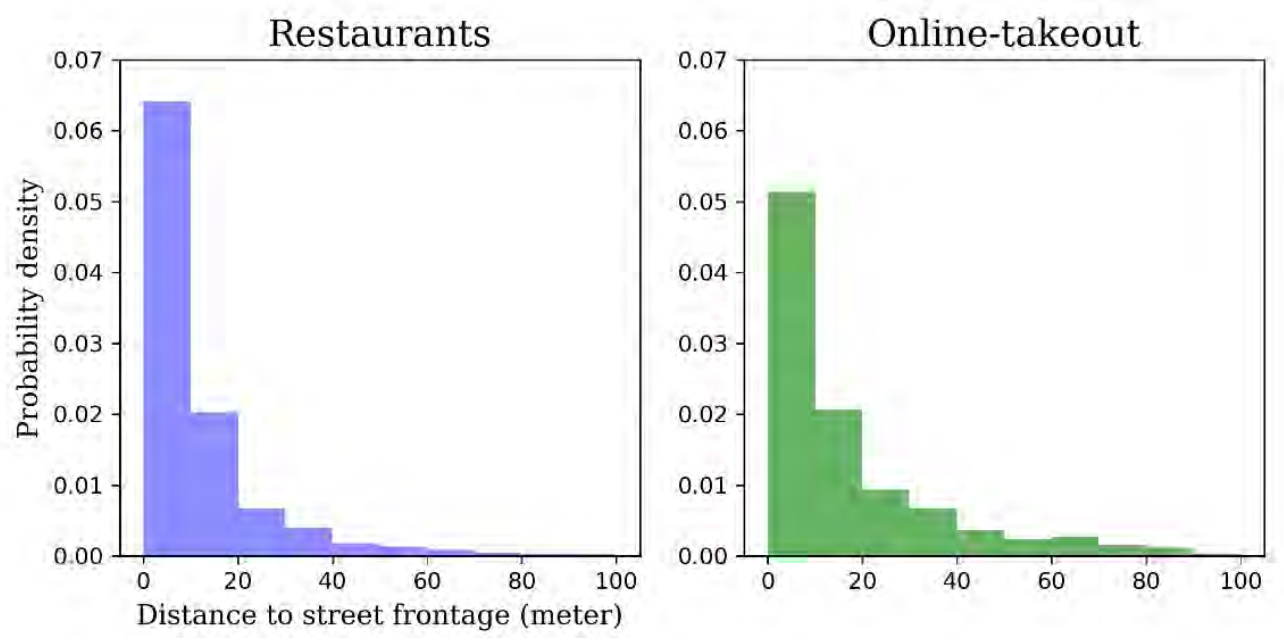

Figure 7. Location of the two shops in terms of distance to street frontages. 


\section{Conclusion and Discussions}

\subsection{Macro Level: Challenges and New Opportunities}

This paper investigates the spatial impact of online to offline service, one of the many ways to make urban life smarter, by a comparative analysis between the conventional restaurants and the online take-out shops. We first identified clear evidence at the city scale that online takeout shops are generally not dependent on agglomeration any more. Compared to the restaurants, whose location has formed eight unique spatial hot spots, the online takeout shops have only one small and probably occasional agglomerative point. Meanwhile, we provide more explicit evidence by directly computing the distance of the two shops to urban commercial centers. We found that most restaurants tend to be located with the smallest distance to urban commercial centers, while online takeout stores tend to move away.

Additionally, we also characterized the location by road network accessibility metric and distance to subway station. Although the results show that both their locations are not sensitive to these metrics, however, we found completely different trends of the sale distribution between the two shops. The sale amount of online takeout stores does not depend on the distance to the subway station and general accessibility, which is probably due to the natural business model that enables the takeout shops to be independent with local spatial heterogeneity. Here in order to showclearly and integrally the difference between the two shops, we choose a sub-district to visualize the 3D density of the two shops weighted by sales and other factors. In Figure 8, it shows explicitly that most online takeout stores are located farther away from the commercial center of the city, and many takeout stores locate at street segments with a comparatively low between-ness centrality.

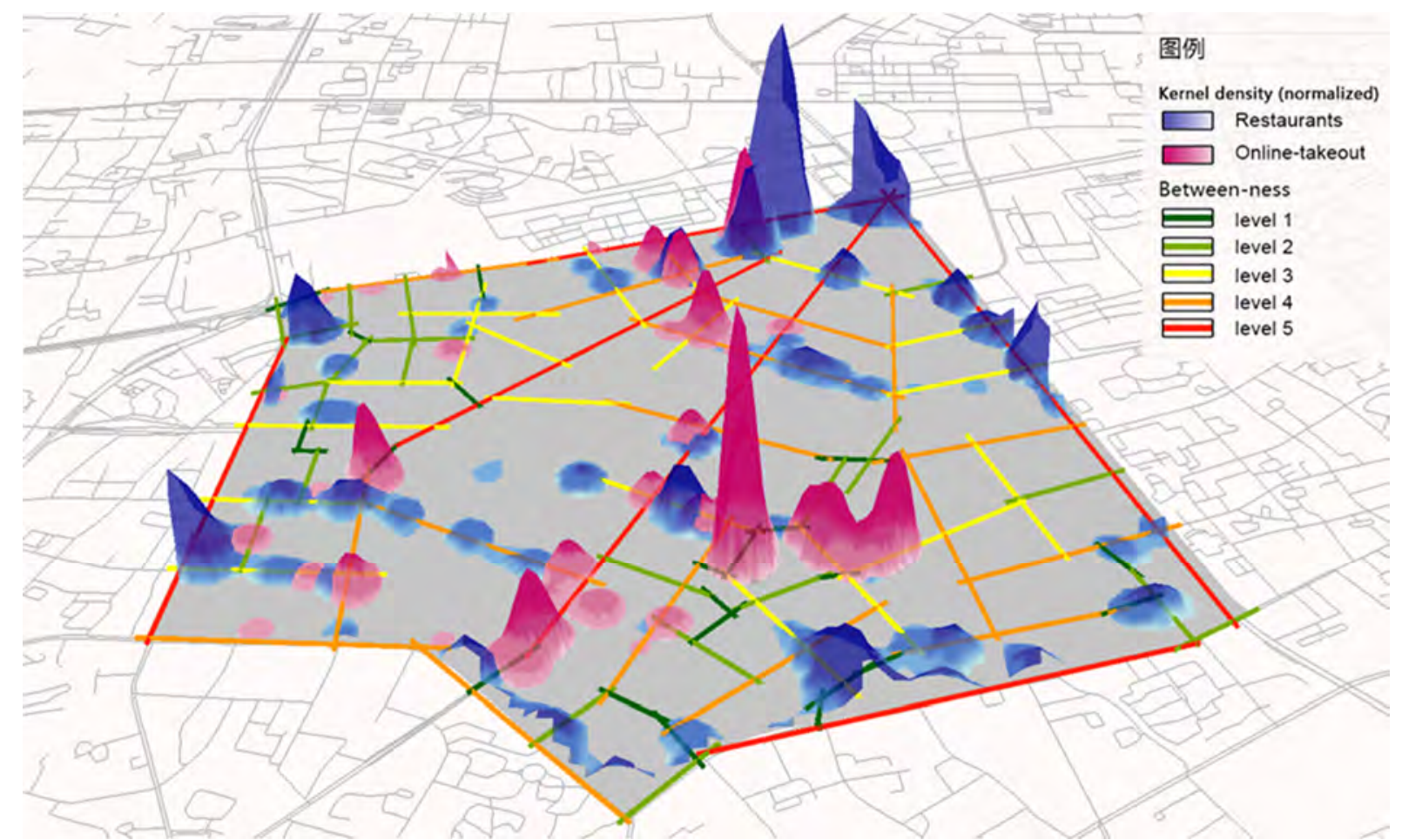

Figure 8. Integrated diagram of the two shops with commercial centers and between-ness centrality. Note there is a large commercial center at the north corner and 4 commercial centers located at the edge of the visualized area with blue peaks.

The locational disparity that characterized by the metrics we use has demonstrated a completely different trends with the conventional urban spatial organization. In other words, the implementation of Smart City technology may transform the spatial competition mechanism that defines the modern urban spatial structure. Specifically, those online takeout servicers might no longer rely their business on spatial clustering, i.e., being close to each other to form commercial centers. Instead they would 
prefer locations away from the centers and those accessible streets to reduce rent cost, given the online platform and the convenient delivery system enables them to attract customers by price, reviews, reputation, and other specialties. This relocation phenomenon could happen with aspatial range of about 5 kilometers considering a conservative delivery time of $30 \mathrm{~min}$.

In our opinion, this spatial organization adjustment could bring both opportunities and challenges to urban development. The challenge is mainly about the development of urban commercial centers and other lower level retail nodes. Considering more and more retail and daily servicers start to connect their business with online platforms, the same story could also happen and finally all of them lead to a general decline of conventional commercial centers. New opportunities thereby rise at the "ordinary" location in conventional urban structure. In the online shopping studies researchers may assert a complementary effect. However, for the $\mathrm{O} 2 \mathrm{O}$ model in our study, those servicers could be completely independent of conventional shops but rely heavily on the delivery system or local transportation situation. Eventually in the new business model, customers get convenience and probably lower price, new servicers gain their revenue, and the old restaurants lose profit. Below we continue to investigate the details of the new opportunities.

\subsection{Micro level: Mixed Land Use and Opening-block Strategies}

At the micro level, we provided a fine estimate of the detailed location characteristics with respect to street frontages. The result reveals that about $18 \%$ of the take out shops have been "relocated" with a distance larger than 40 meters from the street, which we believe could be defined as mixed into the blocks. In contrast, the number of conventional restaurants is only $5 \%$.

We believe that this trend will bring challenger to China's urban development and regulations. Although China's zoning system already includes regulations of mixed land use, such as which type of function could be mixed into certainurban blocks. Such regulations are generally turned into urban management only when the functional mix reality causes social conflict. For instance, although large restaurants are forbidden inside most of the residence blocks, sometimes they do exist as long as no conflicting interests. However, considering the fact that online takeout shops and other "smart" service based on information technology have this tendency to located away from streets, more social conflicts could be triggered from the functional mixture. Therefore, we argue that both the zoning system and the other related urban management in China will face new challenges as the Smart City continue to become a reality.

In another aspect, since most takeout shops choose to be located farther away from the street frontage in order to lower expenses, we may infer that many online takeout shops would be located in the inner area of the residential blocks. Currently, most China's residential neighborhoods are gateway communities, which is considered may cause severer traffic problems. New set of urban development guidelines has been proposed by State Council to address the problem by breaking up superblocks with narrower, one-way streets, as well as opening up and phasing out gated communities (https://www.citymetric.com/fabric/china-s-urban-policy-unit-just-met-first-time-38-years-here-swhat-it-recommended-1904).Hence we argue that at the new era of Smart City such policies should be re-considered to provide sustainability. On one hand, when facilitating the new service industry is one of the policy objectives, the opening block strategy may greatly improve the accessibility of certain "ordinary" locations and thereby pave the way of mixed land use and new development. On the other hand, this process will aggravate the underlying social issue of urban mixture. In conclusion, although this paper has not been based on a survey about the subjective motivation of those online service providers, we have many reasons to believe that Smart City technology could have the same new trends in location as long as they reduce dependence on spatial proximity. Thereby we may imagine that in a real Smart City in the near future it will has a less agglomerative spatial structure, more accessible streets, and more mixed land use, and of course more convenient and intelligent urban life. 


\section{References}

[1]. Applebaum W, 1977, "Marketing Geography: With Special Reference to Retailing" JMR, Journal of Marketing Research (pre-1986)14 123.

[2]. Berry B J L, 1967 Geography of market centers and retail distribution (Prentice-Hall).

[3]. Brueckner J K, 1993, "Inter-store externalities and space allocation in shopping centers" The Journal of Real Estate Finance and Economics7 5-16.

[4]. Bucklin L P, 1967, "The concept of mass in intra-urban shopping" The Journal of Marketing 3742.

[5]. Christaller W, 1966 Central Places in Southern Germany (Englewood Cliffs, N.J., Prentice-Hall).

[6]. Hotelling H, 1990, "Stability in competition", (Springer) pp 50-63.

[7]. Mokhtarian P L, 2004, "A conceptual analysis of the transportation impacts of B2C e-commerce" TRANSPORTATION31 257-284.

[8]. Porta S, Strano E, Iacoviello V, Messora R, Latora V, Cardillo A, Wang F, Scellato S, 2009, "Street Centrality and Densities of Retail and Services in Bologna, Italy" Environment and Planning B: Planning and Design36 450-465.

[9]. Stokvis J R, Cloar J A, 1991, "CRM: Applying shopping center techniques to downtown retailing" Urban Land50 7-11.

[10]. Webber M J, 1972 Impact of uncertainty on location (Canberra: Australian National University Press).

[11]. Weltevreden J W J, 2007, "Substitution or complementarity? How the Internet changes city centre shopping" Journal of Retailing and Consumer Services 14 192-207.

[12]. YAN L, ZHANG S, WANG D, XIE D, CHEN Y, 2016, "Identification and Evaluation of Living Centers System in Shanghai", p 9. 